\title{
The welfare impact of Medicare HMOs
}

\author{
Robert Town* \\ and
}

Su Liu**

We estimate the welfare associated with the Medicare HMO program, now known as Medicare + Choice $(M+C)$. We find that the creation of the $M+C$ program resulted in approximately $\$ 18.7$ billion in consumer surplus and \$52 billion in profits from 1993 to 2000 (in 2000 dollars). This program most likely generated significant net social welfare. However, we find that consumer surplus is geographically unevenly distributed. Prescription drug coverage accounts for approximately $45 \%$ of the estimated consumer surplus for 2000. Consumer surplus increases in the number of plans in a county, and most of the increase in welfare is due to increased premium competition.

\section{Introduction}

In 1982, Congress passed the Tax Equity and Fiscal Responsibility Act (TEFRA), which mandated the provision of managed care plan options to Medicare beneficiaries. Under the statute, the Health Care Financing Administration (HCFA), now called the Centers for Medicare and Medicaid Services (CMS), was directed to contract with health maintenance organizations (HMOs) to provide a managed care option to Medicare enrollees. Under Medicare+Choice $(\mathrm{M}+\mathrm{C})$, the current name for the program, Medicare enrollees can forgo the traditional, fee-for-service (FFS) Medicare program and enroll in a qualified HMO. The HMO agrees to provide health insurance coverage for all FFS, Medicare-covered services (Parts A and B) for the enrollee in exchange for a per-capita payment from CMS. In addition, HMOs are free to offer more generous benefits than available in the standard, FFS program. The rationale underlying TEFRA is that HMOs may be more efficient at providing care, thereby reducing federal Medicare expenditures. Medicare enrollees may also benefit from the option to enroll in competing HMOs that would probably offer a more generous benefit package than available in the traditional FFS program.

We exploit the institutional properties of the Medicare HMO market and use a market-level, plan dataset to estimate the welfare that Medicare beneficiaries receive from the $\mathrm{M}+\mathrm{C}$ program.

*University of Minnesota; rjtown@umn.edu.

** Mathematica Policy Research, Inc.; sliu@mathematica-mpr.com.

We have received helpful comments from two anonymous referees, Mike Chernew, Bryan Dowd, Roger Feldman, Gautam Gowrisankaran, Will Manning, Tom McGuire, Mark Rysman, participants at the 5th Industrial Organization of Health Care Conference in 2001, the 13th Annual Health Economics Meetings in 2002, seminar participants at the University of Chicago and Stanford University, and the Editor of this issue. We thank Rachel Halpern for providing us with her data. We also thank the Veterans Administration Management Science Group for financial support of the Annual Health Economics Meetings. 
We use methods suggested by Berry (1994) to estimate the preferences Medicare beneficiaries have over differentiated HMOs. In this framework, utility is posited to be a function of the plan characteristics (both observed and unobserved by the researcher) and plan premium.

Our estimates indicate that the Medicare HMO program added approximately \$18.7 billion in consumer surplus and $\$ 52.0$ billion in HMO profits from 1993 to $2000 .^{1}$ That is, the federal government's creation of an alternative health insurance market to Medicare's FFS insurance resulted in substantial welfare gains. In 2000, the average Medicare enrollee earned $\$ 113$ in consumer surplus because the Medicare+Choice program was available. This translates into $\$ 62$ in consumer surplus per $\mathrm{M}+\mathrm{C}$ enrollee per month. To calculate the net social surplus created by $\mathrm{M}+\mathrm{C}$, we must compare the benefits of the program to its costs. The cost of the program to the federal government is the cost of $\mathrm{M}+\mathrm{C}$ enrollees if they were to remain in the FFS system relative to its outlays for those enrollees in the $\mathrm{M}+\mathrm{C}$ sector. We estimate that the program increased welfare if the cost of enrolling the typical Medicare HMO enrollee in the Medicare FFS program is not less than $71 \%$ of the average payment made to Medicare HMOs. A conservative estimate of the cost of insuring the typical M+C enrollee in the FFS system is $80 \%$ of the average FFS expenditure. Even under this conservative estimate, the total net welfare from the $\mathrm{M}+\mathrm{C}$ program is substantial: $\$ 24.8$ billion.

Our estimates imply that prescription drug coverage plays an important role in generating consumer surplus. In 2000, we estimate that drug benefits account for $45 \%$ of consumer surplus. This translates into an implied annual average value of drug benefits of $\$ 445$ for those who enrolled in an $\mathrm{M}+\mathrm{C}$ plan that offered drug benefits. In light of the recent debate over whether and how to add prescription drug benefits to Medicare, this finding has significant policy implications. Our results indicate that $\mathrm{M}+\mathrm{C}$ plans can deliver valued prescription drug benefits, and thus policies that promote $\mathrm{M}+\mathrm{C}$ plans as the vehicle to deliver prescription drug coverage to Medicare enrollees can generate significant welfare.

Although the benefits from the $\mathrm{M}+\mathrm{C}$ program are large, they are not evenly distributed across the country. In 2000, most counties, accounting for approximately a quarter of all Medicare beneficiaries, did not have an $\mathrm{M}+\mathrm{C}$ plan, and very few counties (less than $6 \%$ ) had four or more competing plans. Our estimates imply that consumer surplus dramatically increases in the number of plans in a county. For example, in 2000, mean consumer surplus in one-plan counties is $\$ .91$ per beneficiary per month. In counties with four plans, mean consumer surplus is approximately 12 times greater than in monopoly counties. Since we have estimated structural parameters, we can decompose the sources of the differences in consumer surplus between one-plan and four-plan counties by performing several simulation exercises. We find that most $(81 \%)$ of the difference in consumer surplus between one-plan and four-plan counties is driven by decreases in plan premiums due to increased competition. The remaining difference in consumer surplus is divided between the greater availability of drug benefits in four-plan counties (8\%), increases in non-drug-plan quality ( $8 \%$ ), and increases in product diversity $(3 \%)$.

As a by-product of the welfare calculation, we can estimate Medicare enrollees' semielasticity of demand for HMOs and that figure is of independent interest. Our results indicate that demand for $\mathrm{M}+\mathrm{C}$ plans is inelastic. We estimate the monthly semi-elasticity to be -.009 for a typical $\mathrm{HMO}-\mathrm{a} \$ 1$ increase in the premium reduces $\mathrm{HMO}$ enrollment by $.9 \%$. Conditional on charging a positive premium, the median plan elasticity is -.33 .

Not only are the results relevant for understanding the impact of the current Medicare system, they are also pertinent for evaluating Medicare reform proposals. Several commentators have observed that the current Medicare FFS system most likely creates a large welfare loss, and they have proposed replacing the fee-for-service system with a form of managed competition (e.g., Dowd, Feldman, and Christianson, 1996). The efficacy of these reforms will depend largely on their ability to generate meaningful competition between HMOs. Our analysis bears directly on this matter. We find that managed competition can generate significant consumer surplus for

\footnotetext{
${ }^{1}$ Figures are in 2000 dollars.
} 
the elderly population if there is significant HMO competition. However, generating sufficient HMO competition appears to be difficult. Our results also hint at the potential political difficulty of implementing such reforms. According to our estimates, managed care plans appear to gain disproportionately from $\mathrm{M}+\mathrm{C}$ participation, and programs that mostly benefit HMOs may be politically unpalatable to the populace.

The rest of the article has is structured as follows. Section 2 discusses the Medicare HMO program. Section 3 sets out our empirical framework, and Section 4 discusses the data. Section 5 presents the results. Section 6 concludes.

\section{Medicare HMOs}

- Medicare began to permit HMO participation in 1972. The Medicare program's interest in HMOs as an alternative method for delivering care grew during the 1970s, and it began experimenting with HMOs as demonstration projects in the late 1970s and early 1980s. By 1980, however, HMOs had virtually no role in the Medicare program-only one managed care organization had signed a risk contract (Group Health Cooperative of Puget Sound).

In 1982, with the passage of TEFRA, Congress mandated the provision of managed care plan options to Medicare beneficiaries. The statute allows Medicare beneficiaries to enroll in risk or cost contract HMOs. Plans wishing to offer a Medicare risk product sign annual contracts with Medicare's administrative agency, CMS, to provide benefits to individuals who voluntarily enroll with the HMO. In exchange for their participation, the plans receive a payment for each beneficiary they enroll. From 1982 until 1997, Medicare paid HMOs 95\% of its projected cost (Parts A and B) to treat a similar enrollee in the FFS program, where "similar" was defined using age, gender, welfare status, institutional status, and location. This payment is called the average adjusted per-capita costs (AAPCC). Under this structure, geographic units are counties, so the CMS payment (the AAPCC) varies by county and over time. In 2000, approximately 39 million individuals were enrolled in one of Medicare's three main eligibility categories: aged (those over 65 years old), disabled, and end-stage renal dialysis. Medicare HMOs receive different payments for enrollees who are in the different Medicare programs.

In Table 1 we present the quartiles of the CMS payment rates in 1993 and 2000 (along with other summary statistics that we discuss later). The spread of the AAPCC in both years is rather large $-25 \%$ of the 1993 median and $20 \%$ of the 2000 median. The determination of the AAPCC (until 1998) was based on a five-year moving average of Medicare's realized cost, with the moving average window starting three years prior to the current year. The payment rate in period $t$ is calculated using Medicare's realized costs in years $t-3$ to $t-8$. There is a large variation in the AAPCC across counties and over time within a county.

In counties where the Medicare HMO option is available, Medicare beneficiaries can choose either to enroll in an HMO or to remain in the FFS sector. If the beneficiary remains in the FFS sector, he or she is automatically enrolled in Part A of the program, which covers hospital stays (with a small deductible) and catastrophic care. In addition, the individual can (and most Medicare-eligible individuals do) enroll in Part B for a premium (in 1995 it was $\$ 42.50$ per month). Part B covers physician services with a $20 \%$ coinsurance; lab and diagnostic tests; outpatient services with a $20 \%$ co-payment; and mental health care with a $50 \%$ co-payment. Not covered in Medicare's Part A and B program is long-term care, prescription drugs, preventive care, dental care, and eye care. Most Medicare FFS enrollees also purchase Medigap insurance coverage, which supplements Medicare Parts A and B by offering additional benefits such as prescription drug coverage. In 1998, 30 million FFS Medicare enrollees purchased Medigap coverage (Bell, 1999).

CMS requires HMOs to provide a minimum set of benefits - essentially equal to those offered under Parts A and B of the FFS Medicare program. In addition, HMOs can negotiate with CMS to provide additional benefits, including (but not limited to) prescription drugs, eye care, dental coverage, and preventive care. HMOs can also charge a premium to their enrollees subject to 
TABLE $1 \quad$ Summary Statistics

\begin{tabular}{lcc}
\hline \multicolumn{1}{c}{ Variable } & 1993 & 2000 \\
\hline Percentage of counties with at least one HMO & $8.9 \%$ & $27.9 \%$ \\
Average number of enrollees per plan & 3,488 & 2,983 \\
& $(8,672)$ & $(7,399)$ \\
Percentage of plans offering drug coverage & $37.1 \%$ & $74.5 \%$ \\
Average premium & $\$ 46.82$ & $\$ 20.74$ \\
& $(\$ 35.04)$ & $(\$ 25.51)$ \\
Percentage of plans charging zero premium & $25.0 \%$ & $39.4 \%$ \\
Mean medigap premium & $\$ 101.16$ & $(22.2)$ \\
& $(15.0)$ & $10.4 \%$ \\
Mean Medicaid enrollment rates for Medicare eligibles & $10.5 \%$ & $(61.7)$ \\
CMS payment quartiles & $\$ 305, \$ 344, \$ 391$ & $\$ 401, \$ 433, \$ 477$ \\
HMO medicare penetration & $(71.6)$ & $15.2 \%$ \\
Total number of county/plans observations & $4.8 \%$ & 2,173 \\
Number of counties & 512 & 3,208 \\
\hline
\end{tabular}

Note: Figures in 2000 Dollars. Standard deviations in parentheses.

CMS approval. ${ }^{2}$ HMOs observe the announced AAPCC in each county and evaluate whether to provide service in the county. Conditional on operating in a county, the HMO then decides on the set of benefits and the premium given Medicare beneficiaries' preferences for the HMO, the competitive environment, and their expected cost. These benefits and premiums can and do vary by county.

Until the mid-1990s, HMO participation in the Medicare program was lackluster. In 1993, 11 years after the passage of TEFRA, only $5 \%$ of Medicare beneficiaries were enrolled in an HMO and only 9\% of counties had a Medicare HMO. From 1993 until 1998, there was a substantial increase in the number of HMOs operating and a simultaneous increase in the number of Medicare beneficiaries enrolling in HMOs. Figure 1 graphs the average number of HMOs per county. In 1993 there were .16 HMOs per county, and that number increased each year until 1998, when there were .81 HMOs per county. A large number of HMOs exited the Medicare market in 2000, reducing the average number of HMOs per county to .68 .

The decline in the number of HMOs corresponds to changes in the methodology for determining the CMS payment to HMOs enacted under the Balanced Budget Act (BBA) of 1997. The BBA fundamentally modified Medicare's payment methodology. ${ }^{3}$ Although the changes in the payment formula are rather technical, for our purposes the important feature of the new payment formula is that now updates to the county payments are divorced from changes in the Medicare FFS experience in the county. ${ }^{4}$ For most counties the post-BBA payment formula led to a substantial decrease in CMS payment rates over what the HMOs would have received prior to the BBA. It is estimated that the BBA methodology lowers the payments to HMOs by an average of 6\%. (Congressional Budget Office (1999).) In addition to reducing the level of CMS payments, the BBA appears to have diminished the variance of the payments across the counties. According to Table 1, the 1993 interquartile range divided by the median is .25. In 2000 , the corresponding

\footnotetext{
${ }^{2}$ Currently, CMS is allowing Medicare HMOs to charge negative premiums to enrollees. Over the period of our data, the minimum premium a plan could charge is zero.

${ }^{3}$ With the passage of the BBA, the Medicare HMO program also received its current name: "Medicare+Choice."

${ }^{4}$ The county rates in 1998 and onward are based on the 1997 county rate book and not on the experience of fee-for-service enrollees in each county in the previous years. Those county rates are set equal to the maximum of three rates: blended input price - an adjusted national rate and an area-specific rate; a floor payment designed to increase the rates in low-paying counties; and minimum rate increases of $2 \%$ per year.
} 


\section{FIGURE 1}

MEAN NUMBER OF PLANTS PER COUNTY PER YEAR

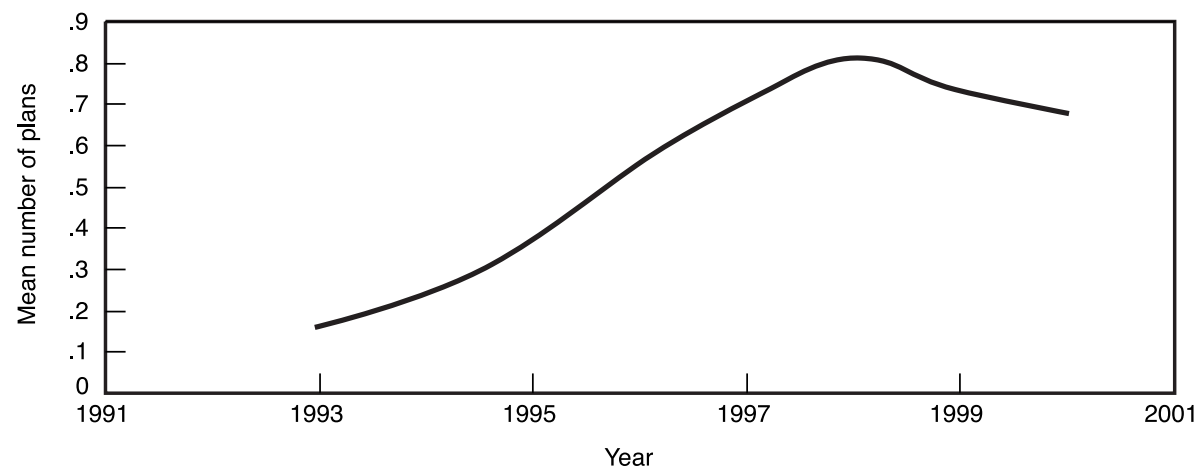

figure is .20. Prior to the enactment of the BBA, plans were required to have $50 \%$ of their enrollees in a service area to be from the non-Medicare population, and the BBA removed this restriction.

Much of the research studying the HMO Medicare program has focused on risk selection and seeks to ascertain whether Medicare HMO enrollees have cost characteristics different from those of the general Medicare population. This literature generally, but not unanimously, concludes that HMOs receive a lower-cost pool of enrollees than the general Medicare population; however, the estimated magnitude of the cost differential varies widely (Hellinger and Wong, 2000).

Although understanding the cost of treating the HMO population in the FFS system is important for calculating the optimal CMS payment level, it is only one component of the proper welfare calculation. Medicare HMOs are a different product compared with the FFS system, as they offer different benefits and a different approach to care. The fact that Medicare beneficiaries have begun to enroll in HMOs in substantial numbers suggests that those beneficiaries receive welfare above what they would get in the FFS sector. In the next section we outline our methodology for estimating the magnitude of this welfare.

\section{The empirical framework}

- Estimating consumer surplus. The first step in estimating consumer welfare is to specify and estimate the parameters of a utility function. Our approach is similar to those of Trajtenberg (1989), Berry and Waldfogel (1999), Berry, Levinsohn, and Pakes (1999), Petrin (2002), Rysman (forthcoming), and Goolsbee and Petrin (2001). HMOs are differentiated products, as they differ in the benefit generosity and charge differential premiums. We estimate the parameters of a utility function from a discrete-choice model of consumer behavior in a differentiated-products framework. We then use these parameter estimates to formulate measures of welfare. ${ }^{5}$

Our data are aggregated to the plan/county level. Berry (1994) shows that with aggregated, market-level data, it is possible to derive a simple, linear regression equation that corresponds to a discrete-choice, nested logit model of individual consumer demand as articulated by Cardell (1997). In our specification there is one nest and three groups: enrollment in an HMO offering prescription drug coverage, enrolling in an HMO that does not offer prescription drug coverage, or remaining in the standard fee-for-service Medicare program. The specification allows for Medicare enrollees to have differing views on the desirability of a given managed care plan.

Specifically, we begin by assuming that utility is given by

$$
u_{i j t}=\beta_{1} d_{j m t}+\beta_{2} d_{j m t}^{97}+\beta_{3} \ln \left(a g e_{j m t}\right)-\alpha p_{j m t}+\xi_{j m}+\varepsilon_{j m t}+\zeta_{i \text { Group }}(\sigma)+(1-\sigma) v_{i j m t} .
$$

Here $u_{i j t}$ is the indirect utility of Medicare beneficiary $i$ who lives in county $m$ of enrolling in

${ }^{5}$ Hausman (1997) proposes a different approach to estimating welfare in a differentiated-products framework. 
plan $j, d_{j m t}$ is a dummy variable indicating whether prescription drug benefits are offered by plan $j$ in county $m, d_{j m t}^{97}$ is a dummy variable indicating whether prescription drug benefits are offered in 1997 or thereafter, age is the $\mathrm{M}+\mathrm{C}$ experience of the plan in the county, $p_{j m t}$ is the monthly premium, $\xi_{j m}$ is the unobserved, time-invariant component of plan desirability, and $\varepsilon_{j m t}$ is the shock to plan desirability. We allow the value of the prescription drug benefit to vary over time, as a large number of efficacious and expensive drugs entered the marketplace during the latter half of the 1990s. The unobserved components of quality include the plan benefit structure (e.g., eyeglass, dental, and mental health coverage as well as co-pay amounts), the breadth and quality of the provider network, and the administrative structure of the HMO bureaucracy through which the enrollee must navigate.

The experience of the plan within the county as measured by age $e_{j m t}$ is also probably related to plan quality for at least three reasons. First, there is probably learning by doing in the managing of care for Medicare enrollees. Second, the more established a plan is in a county, the easier it is for the plan to assemble the desired network of providers (Wholey and Burns, 2003). Third, there is evidence that switching costs are important for HMO enrollees, which may imply that the older the plan, the higher its apparent quality (Strombom, Buchmueller, and Feldstein, 2002).

Each enrollee is assumed to have individual-specific preferences over HMOs that offer prescription drug benefits, HMOs that do not offer drug benefits, and the outside option. Differences across individuals in their preferences for plans in different groups are captured by $\zeta_{\text {iGroup }}(\sigma)$, which has a distribution that depends on $\sigma$. There are three Group categories: plans with drug benefits, plans without drug benefits, and the outside good. The individual error term $v_{i j m t}$ is distributed i.i.d., Type I Extreme Value.

The outside good is defined as the enrollee remaining in the Medicare FFS program and purchasing supplemental Medigap coverage. The majority of Medicare FFS enrollees supplement their coverage with a Medigap policy. We obtained premium information on Medigap coverage from the American Association of Retired Persons (AARP). We normalize the unobserved quality of the Medicare FFS program with Medigap coverage to zero. The utility of the outside good is then $u_{i 0 t}=-\alpha p_{0 m t}+\mu_{i 0}$, where $p_{0 m t}$ is the Medigap premium.

A well-known problem associated with estimating the parameters in equation (1) is that the HMO-specific error term, $\xi_{j m}+\varepsilon_{j m t}$, is most likely correlated with the premium, implying that OLS estimates of (2) will generate biased price coefficients. Our estimation strategy uses first differences to remove $\xi_{j m}$ from the estimation equation. ${ }^{6}$ The plan-specific shock, $\varepsilon_{j m t}$, is still potentially correlated with the variables on the right-hand side. We will use an instrumentalvariables (IV) technique to correct for this correlation between the error term and the endogenous variables. The key identifying assumption (outside of the orthoganality of the instruments and $\varepsilon_{j m t}$, which we discuss below) is that plans do not observe shocks to plan quality when deciding on whether to offer a prescription drug benefit $-\xi_{j m}$ may be correlated with the drug coverage decision, but $\varepsilon_{j m t}$ is not. This is the standard identifying assumption in the literature (e.g., Berry, Levinsohn, and Pakes (1995), Nevo (2001), and Petrin (2002)). ${ }^{7}$ The parameters in (1) can be estimated using the following linear, share equation:

$$
\begin{aligned}
& \Delta\left(\ln \left(\mathrm{s}_{\mathrm{jmt}}\right)-\ln \left(\mathrm{s}_{\text {out }, \mathrm{mt}}\right)\right) \\
& \quad=\beta_{1} \Delta \mathrm{d}_{\mathrm{jmt}}+\beta_{2} \Delta \mathrm{d}_{\mathrm{jmt}}^{97}+\beta_{3} \Delta \ln \left(\mathrm{age}_{\mathrm{jmt}}\right)-\alpha\left(\Delta \mathrm{p}_{\mathrm{jmt}}+\Delta \mathrm{p}_{0 \mathrm{mt}}\right)+\sigma \Delta \ln \left(\mathrm{s}_{\mathrm{j} \mid \mathrm{d}_{\mathrm{jmt}}}\right)+\Delta \varepsilon_{\mathrm{jmt}},
\end{aligned}
$$

${ }^{6}$ We use a first-difference instead of a fixed-effect estimator because the evidence indicates that there is significant autocorrelation in the shock to plan quality, $\varepsilon_{j m t}$. If $\varepsilon_{j m t}$ follows a random walk, then the standard instrumental-variables, first-difference estimator is efficient and generates unbiased estimates of the standard errors. The evidence presented in Section 5 indicates that $\varepsilon_{j m t}$ is, in fact, close to a random walk (i.e., there is little autocorrelation in $\Delta \varepsilon_{j m t}$ ).

${ }^{7}$ Ideally, we would like to relax this assumption because here, as in most other applications, firms probably select the observed components of product quality with knowledge of the other, unobserved dimensions of product quality. However, relaxing this assumption requires locating difficult-to-find valid instruments or formulating a more detailed model of the benefit-structure decisions of plans. Both approaches are difficult to implement and beyond the scope of this article. 
where $\Delta$ is the first-difference operator, $s_{j m t}$ is the share of enrollees (relative to all potential purchasers, not just those beneficiaries who select an HMO) who enroll in plan $j$ in county $m$ in period $t, s_{j \mid d_{j m t}}$ is the within-HMO drug category market share, and $s_{\mathrm{out}, m t}$ is the share of eligibles who purchase the outside good.

To estimate the parameters in (2) we need to specify both the total size of the market and the nature of the outside good. In our specification, there are two classes of products: Medicare HMOs and Medicare FFS with supplemental Medigap coverage. This is a simplification of the actual choices facing Medicare eligibles. Approximately $10 \%$ of the Medicare population is also eligible for Medicaid benefits. Medicaid benefits are more generous than those granted in the Medicare program. We assume that Medicare beneficiaries who are eligible for Medicaid benefits will enroll in the Medicaid program and will not consider enrolling in an HMO or obtain Medigap coverage. We use state-level Medicaid enrollment information to adjust the size of the market. That is, $s_{j m t}=q_{j m t} / M_{m t}\left(1-\right.$ Medicaid $\left._{m t}\right)$, where $q$ is the number of plan enrollees, $M$ is the number of Medicare eligibles, and Medicaid is the statewide Medicaid enrollment rate for Medicare eligibles. ${ }^{8}$

Also, many Medicare enrollees receive subsidized insurance through their former employer, and this subsidy can often be used to purchase supplemental insurance or to enroll in an $\mathrm{M}+\mathrm{C}$ plan. We are unaware of any publicly available, county-level (or state-level) information on the number of Medicare enrollees who receive this benefit, so we cannot control for this possibility in the estimation. However, we do not view this omission as seriously biasing our results. An employer's decision on whether to offer an HMO in the menu of retiree benefits will most likely depend on the premium charged by the HMO. That is, employers are likely to have some price sensitivity, and, insofar as retiree benefits impact HMO choice, we want our parameters to reflect that possibility. Second, many retiree benefit packages do not cover the full cost of supplemental insurance. Thus, marginal price differences are likely to be paid by the enrollee, making that individual's marginal decisions similar to those of enrollees who do not have as-generous retiree benefits.

Several features of the data make it well suited for the Berry framework. We have multiple observations on many different markets, and these markets experience significant entry and exit. Importantly, the geographic scope of each market is well defined. As discussed in the previous section, the Medicare rules specify that each county is a separate entity for the purposes of setting premiums and benefits. Thus, we have market-level as well as HMO-level variation in the data.

Instruments. The plan demand shock, $\Delta \varepsilon_{j m t}$, is potentially correlated with the change in premiums, implying that first-differenced, OLS estimates of the coefficients are probably biased. We correct for this possible bias using an IV framework where $\Delta\left(p_{j m t}+p_{0 m t}\right)$ and $\Delta \ln \left(s_{j \mid d_{j m t}}\right)$ are endogenous variables. As we first-difference the data, the identification of the parameters comes from within-plan changes in the instruments.

We construct instruments using two strategies. First, we use supply-side county-level variables that change across time. Those variables are the one-year lagged numbers of hospitals and hospital beds. The lagged values of the number of hospitals and hospital beds should be valid instruments because they impact the HMOs' relative bargaining power with providers and thus their cost structure.

The second set of instruments is the minimum, maximum, and mean of the premiums charged by the plan in the other counties in which it operates and the corresponding CMS payment rates in those same counties. The mean number of competing plans in those counties is also included in the instrument set. The use of the functions of premiums in other counties as instruments is a strategy similar to one used by Nevo (2001) and Hausman (1997). The identification assumption is that shocks to marginal cost will be reflected in changes in premiums in the other counties, holding the characteristics of the other counties constant, and those shocks are uncorrelated with changes in unobserved plan quality. The payment rate in the other counties serves two purposes as instruments. First, the number of plans in the service area is probably correlated with the

${ }^{8}$ Our parameter estimates are largely insensitive to adjustments in the size of the market.

(c) RAND 2003. 
generosity of the payment rate, and the number of plans should be correlated with both plan premium and $s_{j \mid d_{j m t}}$. Second, we wish to control for payment rate in using nearby premiums as instruments. In total we have ten instruments for two endogenous variables.

Consumer surplus calculation. Once the parameters of (1) are estimated it is straightforward to calculate the annual consumer surplus for each county. We denote the annual consumer surplus per Medicare beneficiary in a county in a given period by $W_{m t}$. Given our assumptions and the parameter estimates, McFadden (1983) shows that the expected consumer surplus from the $\mathrm{M}+\mathrm{C}$ program for the representative person is

$$
W_{m t}=\frac{12}{\hat{\alpha}}\left((1-\hat{\sigma}) \ln \left(D_{0 m t}+D_{1 m t}+e^{-\hat{\alpha} p_{0 m t} /(1-\hat{\sigma})}\right)\right) \quad \text { and } \quad D_{d m t}=\sum_{k \in \Lambda_{d m t}} e^{\hat{u}_{k m t} /(1-\hat{\sigma})}
$$

where $\hat{u}_{j m t}=\hat{\xi}_{j m}+\hat{\varepsilon}_{j m t}+\hat{\beta}_{1} d_{j m t}+\hat{\beta}_{2} d_{j m t}^{97}-\hat{\alpha} p_{j m t}$ ( signifies estimated parameters) and $\Lambda_{d m t}$ is the set of plans operating in drug category $d=\{0,1\}$. The welfare calculation in (3) measures the utility an individual receives above his or her expected utility from remaining in the Medicare FFS system. Once we calculate county-level welfare, it is straightforward to aggregate that welfare to national levels. In (3) we are dividing the surplus by the marginal utility of a dollar.

Estimating HMO profits. Total welfare is the sum of consumer, producer surplus, and net government expenditures. To fully account for the welfare impact of $\mathrm{M}+\mathrm{C}$ program, it is necessary to estimate the profits that accrue to HMOs. Estimating HMO profits is not straightforward, since the appropriate measures of costs are unavailable. ${ }^{9}$ In general, given a plan's demand function, it is possible to estimate marginal costs by assuming a static Nash equilibrium in premiums and inverting the plan's first-order condition.

For the profit calculation we assume that the marginal cost of insuring an individual is constant in the number and composition of enrollees. ${ }^{10}$ The profits in county $m$ for plan $j$ can be written as (we are dropping the $t$ subscript for now)

$$
\pi_{j m}=\left(a_{m}+p_{j m}-m c_{j m}\right) s_{j m} M_{m}-F_{m} .
$$

Here $a_{m}$ is the CMS payment rate to the HMOs, $m c_{j m}$ is the marginal cost of an enrollee, $M_{m}$ is the number of Medicare eligibles not enrolled in Medicaid in the county, $F_{m}$ is the fixed cost, which is constant across plans in a given county, and the rest of the notation is the same as before. Assuming static profit maximization, a Nash equilibrium in premiums, and an optimal premium greater than or equal to zero, the first-order conditions are

$$
s_{j m}+\left(a_{m}+p_{j m}-m c_{j m}\right) \frac{d s_{j m}}{d p_{j m}}=0 .
$$

The nested logit assumption implies that $d s_{j m} / d p_{j m}=-\alpha /(1-\sigma) s_{j m}\left(1-\sigma s_{j m \mid d_{j m}}-(1-\right.$ $\left.\sigma) s_{j m}\right)$. Solving (5) for marginal cost gives our estimate of a plan's marginal cost as a function of the data and estimated parameters,

$$
m \hat{c}_{j m}=a_{m}+p_{j m}+\left(\frac{d s_{j m}}{d p_{j m}}\right)^{-1} s_{j m} .
$$

To calculate the profits, we use (6) to form estimates of the marginal cost, $m \hat{c}_{j m}$, and substitute the estimated marginal cost in for $m c_{j m}$ in (4).

${ }^{9}$ Accounting reports are available on a limited basis for $\mathrm{M}+\mathrm{C}$ plans. Using accounting profits to measure economic profits has long been viewed as problematic, and the problems are particularly acute with HMO data.

${ }^{10}$ This assumption implies that there is no adverse selection in this market. Although allowing for adverse selection would clearly be an improvement, it would also substantially increase the difficulty of the problem. If selection is important, we most likely underestimate marginal cost. 
In the $\mathrm{M}+\mathrm{C}$ program, the majority of plans charge zero premiums; they are thus at a corner solution, and we cannot invert the first-order conditions to get an estimate of the marginal cost without making additional assumptions. For plans charging a zero premium, we assume (6) holds with equality. That is, the marginal cost of those zero-premium plans is such that even if they could charge a negative premium, they would charge a zero premium. This inference strategy surely overestimates the plan's marginal cost and thus underestimates variable profits.

To estimate fixed costs, we assume a free-entry equilibrium for each county in each year. That is, assuming common fixed costs across plans within a county (although they may have differing marginal costs) and that they enter in order of their profitability, if there are $N_{m t}$ plans operating in a county $m$ at time $t$, then $F_{m t}$ is bounded by $R_{m t}^{\min }\left(N_{c t}\right) \geq F_{m t}>R_{m t}^{\min }\left(N_{c t}+1\right)$. Here $R$ denotes variable profits and the min superscript denotes the plan with the smallest $R$ in county $m$ in period $t$. Conditional on our measure of $R$ (which is probably underestimated), we can put a rough upper bound on fixed costs by assuming $\hat{F}_{m t}=\hat{R}_{m t}^{\min }\left(N_{m t}\right)$, where the^denotes estimated values. $^{11}$

\section{Data}

- The data in this study come from three sources: CMS, AARP, and the Area Resource File. From CMS, we merge five files on Medicare HMOs to create an HMO/county-level panel dataset. The five CMS files are (i) the State-County-Plan Penetration file; (ii) the Medicare+Choice/ AAPCC Standardized Per Capita Rates of Payment; (iii) Medicare Metropolitan Statistical Area Code File; (iv) the Monthly Report-Medicare Coordinated Care Health Plans; and (v) Annual State Medicaid enrollments.

For plans offering a Medicare HMO risk contract in a county, we assemble information on the plan's enrollment, the premium charged, and indicators of whether the plan offered drug benefits. In addition, for each county in each year we merge in the CMS payment rate (Parts A + B). We deflate the HMO premium and the CMS payment by the Consumer Price Index.

In the CMS penetration files, individual HMO enrollees are assigned to counties according to the enrollees' residence. This implies that for many counties there is an unrealistically high number of HMOs with very low enrollment (fewer than 12 enrollees). For our purposes, an HMO is defined as participating in a county - and is therefore included in the dataset-if the plan has enrolled at least 12 members if the county has fewer than 5,000 eligibles and 35 members if the county has more than 5,000 eligibles. ${ }^{12}$ This definition of county enrollment is similar to the one used by Cawley, Chernew, and McLaughlin (2001).

From the AARP we acquired annual premiums for their Medigap policy Plan F to proxy for the price of the outside good. ${ }^{13}$ Plan F covers deductibles for Parts A and B, skilled nursing, and physician bills above the Medicare payments. The AARP sets annual premiums on a statewide basis, with a couple of exceptions where the premiums are set county by county. The AARP's Medicare supplemental insurance has approximately 2 million enrollees and is one of the largest Medigap plans in the county. As there are few restrictions on who may enroll in the plan and it is offered nationwide, these data are a sensible proxy for the price of Medigap insurance. From the Area Resource File, we merge in data on the number of physicians, hospitals, and hospital beds. These variables are used as instruments in estimating the utility parameters.

Table 1 presents summary statistics for 1993 and 2000, the beginning and end of our data. As discussed earlier, Table 1 shows the large increase in HMO participation in the Medicare program over the period. Over our sample period, the likelihood that a county had a Medicare HMO increased from $9 \%$ to $28 \%$, and the average number of HMOs operating in a county increased

11 This approach to estimating fixed cost uses logic similar to that employed by Berry and Waldfogel (1999) and Bresnahan and Reiss (1990).

12 We discussed this definition with HCFA staff to ensure its reasonableness.

${ }^{13}$ All Medigap plans are classified into 10 different benefit categories. We estimated the parameters using premiums from the other AARP plans and found that the parameter estimates were not quantitatively different from those presented here. 
from .16 to .68 . The average size of a plan's enrollment decreased from 3,488 to 2,983 . Plan benefits became more generous, while the average premium declined markedly. The percentage of plans offering drug benefits increased from $37 \%$ to $75 \%$. Over this period the average premium declined from $\$ 46.82$ to $\$ 20.74$, and the percentage of plans offering a zero premium increased from $25 \%$ to $40 \%$.

\section{Results}

- Utility function parameter estimates. Table 2 presents the estimates of the utility parameters, equation (2), using different specifications. The first column presents the results from our preferred specification - the nested logit. The coefficient on HMO premium is -.0053 and is precisely estimated $(t$-statistic $=-15.1) .{ }^{14}$ The parameter on the logarithm of within-category market share that measures the within-group correlation in errors, $\sigma$, is .58 with a $t$-statistic of 12.3. ${ }^{15}$ This implies significant and correlated heterogeneity in eligibles' preferences over HMOs. That is, all else equal, individuals who enrolled in a plan that offered drug benefits are more likely to switch to another plan offering drugs benefits if faced with a premium increase.

The provision of drug coverage is highly valued by $\mathrm{M}+\mathrm{C}$ enrollees, and that value increased substantially in the later part of the 1990s. The coefficient on drug coverage is .077 ( $t$-statistic $=3.7)$. The coefficient on drug coverage indicator for 1997 and thereafter is 3.6 times larger and is precisely estimated (coefficient $=.28 ; t$-statistic $=8.8$ ). Thus, the coefficient estimates are consistent with the notion that the quality and quantity of marketed prescription drugs increased substantially through the 1990s. We discuss the implied dollar value of prescription drug benefits to Medicare enrollees below. The value of a plan increases with its experience in the county. The coefficient on the logarithm of within-county experience (age) is 1.06, and it also is precisely estimated $(t$-statistic $=23.6)$.

In column 2 we present the results from an alternate, simple logit specification. Here $\sigma$ is constrained equal to zero. The premium coefficient is somewhat smaller, and the coefficients on prescription drug coverage are very small and insignificant. For comparison purposes, column 3 presents the first-differenced, OLS results. The premium coefficient is implausibly positive, and $\sigma$ is significantly lower relative to the IV results. This is consistent with the plan's premium being correlated with the demand shock, and the OLS estimates of these parameters are biased.

The nested logit framework implies a simple closed-form relationship for the HMO's ownprice elasticity. This elasticity is given by

$$
\gamma_{m j}=\frac{\alpha_{1}}{1-\sigma}\left(1-\sigma s_{j \mid H M O}-(1-\sigma) s_{j m}\right) p_{j m}
$$

and is only defined when the HMO charges a nonzero premium. Conditional on the HMO charging a nonzero premium, the mean (unweighted) own-price elasticity is -.29 (median $=-.33$, standard deviation across plans $=.22$ ).

It is instructive to compare our estimates of the price sensitivity of $\mathrm{M}+\mathrm{C}$ enrollees to the enrollees of other health plans in other institutional settings. The price elasticity varies considerably based on the portion of the premium directly paid by enrollees. Furthermore, because many of the $\mathrm{M}+\mathrm{C}$ plans charge a zero premium, the premium elasticity is not defined. Thus, a more meaningful measure of price sensitivity for our purposes is the semi-elasticity, $\partial s_{j} / \partial p_{j} s_{j}$. Our estimates imply that the mean semi-elasticity from a $\$ 1$ increase in the premium is -.009 . A $\$ 1$ increase in the monthly premium is expected to reduce HMO enrollment by $.9 \%$.

14 The autoregressive parameter on $\Delta \varepsilon_{j m t}$ is small (-.07), suggesting that the first-differenced specification is appropriate.

${ }^{15}$ In the Appendix we present the results of the first-stage regressions-the first-differenced regression of $\left(p_{j m t}-p_{0 m t}\right)$ and $\ln \left(s_{j m \mid d_{j m t}}\right)$ on the instruments and the other exogenous variables. If the instruments are weakly correlated with the endogenous variables, then the IV estimates can be plagued by small sample bias. For both cases, the $F$-statistics reject the joint hypothesis that the coefficients on the instruments are zero. 


\begin{tabular}{|c|c|c|c|}
\hline \multirow[b]{2}{*}{ Parameter } & \multicolumn{3}{|c|}{ Dependent Variable is $\ln \left(s_{j t}\right)-\ln \left(s_{0 t}\right)$} \\
\hline & $\begin{array}{c}\text { First-Difference, IV } \\
\text { Nested Logit } \\
\text { (1) }\end{array}$ & $\begin{array}{l}\text { First-Difference, IV } \\
\text { Logit } \\
\text { (2) }\end{array}$ & $\begin{array}{l}\text { First-Difference, OLS } \\
\text { (3) }\end{array}$ \\
\hline $\mathrm{M}+\mathrm{C}$ premium - Medigap premium & $\begin{array}{l}-.0053 \\
(.00035)\end{array}$ & $\begin{array}{l}-.0047 \\
(.00036)\end{array}$ & $\begin{array}{c}.0050 \\
(.00028)\end{array}$ \\
\hline $\ln \left(s_{j \mid d_{j m t}}\right)$ & .58 & - & 0.29 \\
\hline Drug coverage & $\begin{array}{c}.077 \\
(.021)\end{array}$ & $\begin{array}{c}.087 \\
(.021)\end{array}$ & $\begin{array}{l}0.080 \\
(.018)\end{array}$ \\
\hline Drug coverage $\times($ year $\geq 1997)$ & $\begin{array}{c}.28 \\
(.032)\end{array}$ & $\begin{array}{c}.017 \\
(.023)\end{array}$ & $\begin{array}{c}0.14 \\
(.021)\end{array}$ \\
\hline Logarithm of plan age & $\begin{array}{c}1.07 \\
(.045)\end{array}$ & $\begin{array}{c}1.46 \\
(.032)\end{array}$ & $\begin{array}{c}1.30 \\
(.031)\end{array}$ \\
\hline$R^{2}$ (within) & .44 & .29 & .46 \\
\hline$N$ & 8,849 & 8,849 & 8,849 \\
\hline
\end{tabular}

Note: The instrument set is described in Section 3. Annual dummies also included as independent variables.

The estimates on the price sensitivity of HMO enrollees are in line with the previous literature, albeit at the high end of those estimates. We are aware of three studies that have estimated the health plan elasticity of Medicare eligibles. Buchmueller (2000) estimates that University of California retirees have mean health plan price semi-elasticities of $-.007 .{ }^{16}$ Atherly, Dowd, and Feldman (2003) use individual data from the Medicare Current Beneficiary Survey and also find a premium semi-elasticity of -.007 . Using a similar dataset but a different estimation strategy (they do not instrument for premium), they estimate the mean semi-elasticity for an $\mathrm{M}+\mathrm{C}$ plan to be -.004 , approximately half of our estimate.

Cutler and Reber (1998), Royalty and Solomon (1999), and Strombom, Buchmueller, and Feldstein (2002) study the health plan choices of university employees from Harvard, Stanford, and the University of California system, respectively. These studies find consumer semi-elasticities that range from -.005 to $-.004 .{ }^{17}$ Chernew, Gowrisankaran, and Scanlon (2002) find that implied semi-elasticity to be approximately -.004 for a $\$ 1$ increase in monthly premiums for employees of a Fortune 500 firm. ${ }^{18}$

Using equation (6) and the parameter estimates, we are able to make inferences about HMOs' marginal and fixed costs, and we use these estimates to calculate $\mathrm{M}+\mathrm{C}$ plan profits. Our estimates imply that the median monthly marginal cost for an HMO in 2000 is $\$ 400$ and the median fixed cost is approximately $\$ 173,000$ per county per year, or $12 \%$ of estimated total cost. ${ }^{19}$ The typical patient-weighted CMS payment is $\$ 562$. Ignoring the potential for differential selection into $\mathrm{M}+\mathrm{C}$ plans, in the counties in which $\mathrm{M}+\mathrm{C}$ plans have entered, the estimates imply that HMOs are providing care much more efficiently than does the traditional fee-for-service program.

${ }^{16}$ For studies that do not report semi-elasticities, we relied on the semi-elasticity calculations of the literature reported in Chernew, Gowrisankaran, and Scanlon (2002). For studies not cited therein, we calculated the semi-elasticity implied by the reported coefficient estimates at the mean premium and market share.

${ }^{17}$ Because the employers subsidize the premium, there is generally a difference between the individual elasticity and the effective plan elasticity. Cutler and Reber (1998) estimate the plan's premium elasticity to be approximately -2 , while Royalty and Solomon (1999) estimate the plan elasticity to be between -1 and -3 .

${ }^{18}$ If our estimates of plan semi-elasticities were at the middle of the range from the previous literature, implied HMO profits would be approximately $80 \%$ higher. This would be an implausibly high estimate of profits.

${ }^{19}$ According to accounting data from InterStudy, administrative costs for commercial HMOs comprise approximately $13 \%$ of total accounting expenses in 2000 (personal communication with Doug Wholey). Of course, administrative costs and fixed costs are not identical, but they are related, and this does suggest that our estimates of fixed cost are reasonable. 
The welfare impact of Medicare HMOs. With the parameter estimates from Table 2 in hand, we are now able to calculate consumer surplus and total welfare. Table 3 presents the estimated aggregate consumer surplus and profits by year. The 1990s saw substantial growth in the welfare that Medicare beneficiaries receive from having the option to enroll in an $\mathrm{M}+\mathrm{C}$ plan. In 1993 , we estimate that the total consumer surplus was $\$ 467$ million. This translates into an annual average of $\$ 14$ per Medicare eligible. By 2000, consumer surplus had grown to $\$ 4.1$ billion, or $\$ 113$ per Medicare eligible. The total (undiscounted) consumer benefit over the eight-year period from 1993 to 2000 is $\$ 18.7$ billion. These estimates of the consumer surplus are normalized to the outside option of enrolling in the Medicare FFS with Medigap coverage. The benefit structure of the FFS program did not vary significantly over this period, so the reported increase in consumer surplus is most likely due to increases in the value of the $\mathrm{M}+\mathrm{C}$ option rather than the decline in the value of the FFS sector to Medicare enrollees. The growth in consumer surplus came to a halt by 2000 . From 1999 to 2000 , consumer surplus declined by $5 \%$ - possibly a consequence of the passage of the BBA.

According to our estimates, HMOs enjoyed the majority of the benefits of this government initiative. Over the entire sample period, we estimate that HMOs earned over $\$ 52.0$ billion in profits. In the most recent year of our data, 2000, HMO profits are $\$ 8.8$ billion. That translates into an average monthly profit of $\$ 120$ per Medicare HMO enrollee. Over the entire period, the profit margin relative to total revenue is approximately 22\%. The impact of the BBA on HMO profits can be also been seen in Table 3. Profits were growing steadily through the 1990s until 1998, the year in which the BBA went into effect. From 1998 onward, profits declined in each year.

The parameter estimates used to formulate the welfare measures have standard errors. Therefore, the welfare estimates also have standard errors associated with them. The welfare estimates are nonlinear functions of the parameters, so calculation of the standard errors of the estimates cannot be done using linear methods. We calculate the standard errors by taking 250

TABLE 3 Estimated Aggregate Consumer Surplus and Total Government Expenditures on Medicare HMO Enrollees (1993-2000)

\begin{tabular}{|c|c|c|c|c|c|c|}
\hline Year & $\begin{array}{c}\text { Total } \\
\text { Consumer } \\
\text { Surplus } \\
\text { (\$ Millions) }\end{array}$ & $\begin{array}{c}\text { Mean Annual } \\
\text { Consumer } \\
\text { Surplus Per } \\
\text { Medicare } \\
\text { Beneficiary } \\
(\$)\end{array}$ & $\begin{array}{c}\text { Total } \\
\text { Estimated } \\
\text { Profit } \\
\text { (\$ Millions) }\end{array}$ & $\begin{array}{c}\text { Total CMS } \\
\text { Expenditures } \\
\text { on Medicare } \\
\text { HMO } \\
\text { Enrollees } \\
\text { (\$ Millions) }\end{array}$ & $\begin{array}{c}\text { Total } \\
\text { Medicare } \\
\text { HMO } \\
\text { Enrollees } \\
\text { (Millions) }\end{array}$ & $\begin{array}{c}\text { HMO } \\
\text { Penetration } \\
\text { Rate }\end{array}$ \\
\hline 1993 & $\begin{array}{r}467.4 \\
(197)\end{array}$ & 13.95 & $\begin{array}{r}2,482.2 \\
(250)\end{array}$ & $10,963.5$ & 1.79 & .05 \\
\hline 1994 & $\begin{array}{c}720.4 \\
(275)\end{array}$ & 21.66 & $\begin{array}{r}3,281.6 \\
(349)\end{array}$ & $13,867.0$ & 2.27 & .06 \\
\hline 1995 & $\begin{array}{r}1,162.7 \\
(396)\end{array}$ & 33.81 & $\begin{array}{r}4,365.5 \\
(457)\end{array}$ & $19,379.9$ & 3.12 & .08 \\
\hline 1996 & $\begin{array}{r}1,997.2 \\
(537)\end{array}$ & 57.33 & $\begin{array}{r}6,244.5 \\
(622)\end{array}$ & $27,120.0$ & 4.72 & .11 \\
\hline 1997 & $\begin{array}{r}2,749.0 \\
(698)\end{array}$ & 77.95 & $\begin{array}{r}8,377.7 \\
(780)\end{array}$ & $35,135.3$ & 5.28 & .13 \\
\hline 1998 & $\begin{array}{r}3,291.6 \\
(816)\end{array}$ & 92.53 & $\begin{array}{r}9,320.1 \\
(910)\end{array}$ & $39,445.4$ & 5.92 & .15 \\
\hline 1999 & $\begin{array}{r}4,208.7 \\
(932)\end{array}$ & 117.19 & $\begin{array}{r}9,166.1 \\
(971)\end{array}$ & $41,629.1$ & 6.30 & .16 \\
\hline 2000 & $\begin{array}{r}4,060.9 \\
(911)\end{array}$ & 112.71 & $\begin{array}{r}8,757.2 \\
(917)\end{array}$ & $41,726.3$ & 6.19 & .15 \\
\hline Totals & $\begin{array}{r}18,657.9 \\
(4,756)\end{array}$ & 72.96 & $\begin{array}{r}51,994.9 \\
(5,254)\end{array}$ & $\begin{array}{c}229,266.5 \\
-\end{array}$ & $\begin{array}{l}- \\
-\end{array}$ & - \\
\hline
\end{tabular}

Figures in 2000 dollars. Standard deviations of estimates in parentheses. 
draws from the estimated asymptotic distribution of the utility parameters and then calculating the resulting welfare from each draw. Table 3 presents the standard deviation of the distribution of the welfare estimates. The standard deviation is about $22 \%$ of the consumer surplus estimate and about $10 \%$ of the profits estimate.

Table 3 also presents the total CMS payments to HMOs over the corresponding period. The payments range from $\$ 10.9$ billion in 1993 to over $\$ 40$ billion in 2000 . The net welfare from this government program will be given by ${ }^{20}$

Net Welfare $=\left(C S_{H M O}-C M S\right.$ Payments $)-\left(C S_{F F S}-\right.$ Expect Cost under FFS $)+H M O$ profits.

Here $C S_{x}$ denotes consumer surplus attributable to program $x$. We have normalized $C S_{H м O}$ so that $C S_{F F S}=0$. According to our estimates, the $\mathrm{M}+\mathrm{C}$ program generated positive societal welfare as long as the cost of treating those HMO enrollees under the FFS system is less than $71 \%$ of the actual payments made to the HMOs. Some policy analysts would argue that we should exclude HMO profits in this political welfare accounting. If we do so, the $71 \%$ figure jumps to $92 \%$. The CMS payments were originally set to be $95 \%$ of the expected cost of treating Medicare enrollees in a given county, so even if we ignore $\mathrm{HMO}$ profits in the welfare calculations, the $\mathrm{M}+\mathrm{C}$ program still may have generated positive net welfare.

There is evidence on the expected cost of treating the Medicare HMO enrollees under the counterfactual that they remained in the FFS program (Hellinger and Wong, 2000). While most of the research indicates that Medicare HMOs receive favorable selection, the estimates of the magnitude vary substantially, and some studies find no selection effect at all. Morgan et al. (1997) find that HMOs enroll healthier Medicare beneficiaries and that sicker beneficiaries are more likely to disenroll from HMOs. Riley et al. (1996) estimate that HMO enrollees, if enrolled in the Medicare FFS program, would cost $12 \%$ less than the average Medicare beneficiary. Riley et al. used data from autumn 1994. M+C enrollment has grown substantially since then, and their estimate probably overstates the current cost differentials. Brown et al. (1993) estimate that a typical HMO enrollee would cost $10 \%$ less than the average Medicare FFS beneficiary. Like Riley et al., their work uses data taken from the early 1990s, before the rise of Medicare HMOs. Several studies have found little difference between Medicare HMO and FFS enrollees. Rogers and Smith (1995) find no cost differential between the typical Medicare FFS enrollee and the average Medicare HMO enrollee. Similarly, Dowd et al. (1996), using data from Minneapolis in the late 1980s, find no evidence that Medicare HMOs attract a healthier population. Using aggregate data from the post-BBA period, Town (2003) finds that changes in the county $\mathrm{M}+\mathrm{C}$ enrollment do not affect the actual FFS expenditures in that county.

If we conservatively assume that the cost of treating $\mathrm{M}+\mathrm{C}$ enrollees in the FFS system is $80 \%$ of the HMO payment rate, the welfare gain from the $\mathrm{M}+\mathrm{C}$ program is a substantial $\$ 24.8$ billion. If the cost of treating M+C enrollees in the FFS system is $95 \%$ of the payment, then the net welfare gain is estimated to be $\$ 59.2$ billion. Finally, if there is no cost differential between the two sectors, then the $\mathrm{M}+\mathrm{C}$ program generates $\$ 70.6$ billion in welfare.

In Table 4 we present the mean monthly per-capita consumer surplus, HMO penetration, and the percentage of plans offering drug benefits by the number of plans operating in the county for 2000. Several features displayed in Table 4 are worth mentioning. First, most counties do not have a Medicare $\mathrm{HMO}$ - there are 2,313 counties with over 11.9 million Medicare beneficiaries without an $\mathrm{M}+\mathrm{C}$ plan. Over a quarter of Medicare enrollees receive no benefit from the $\mathrm{M}+\mathrm{C}$ program. Second, consumer welfare and the HMO penetration rate is, for the most part, steadily and often dramatically increasing in the number of plans offered in the county. We explore the relationship in greater detail in the next subsection. Third, conditional on an $\mathrm{M}+\mathrm{C}$ plan operating in a county, the benefits of the Medicare HMO program are still not widely dispersed. In counties with one plan, the average monthly consumer surplus per Medicare beneficiary is $\$ .91$, while in counties with four plans, the average consumer surplus is $\$ 11.87$. In Figure 2 we plot the

${ }^{20}$ In this formulation we are excluding the loss in provider profits due to a change in the number of FFS enrollees. (c) RAND 2003. 
TABLE 4 Monthly Consumer Surplus, HMO Penetration, and Percentage of Plans Offering Drug Benefits by Number of HMOs Operating in the County in 2000

\begin{tabular}{|c|c|c|c|c|c|c|}
\hline $\begin{array}{l}\text { Number of } \\
\text { Plans }\end{array}$ & $\begin{array}{l}\text { Mean Per- } \\
\text { Capita } \\
\text { Consumer } \\
\text { Surplus } \\
\quad \$)\end{array}$ & $\begin{array}{c}\text { Mean CMS } \\
\text { Payment } \\
\text { Rate } \\
(\$)\end{array}$ & $\begin{array}{c}\text { Mean HMO } \\
\text { Penetration } \\
(\%)\end{array}$ & $\begin{array}{c}\text { Percentage } \\
\text { of Plans } \\
\text { Offering } \\
\text { Drug } \\
\text { Benefits }\end{array}$ & $\begin{array}{c}\text { Number of } \\
\text { Counties }\end{array}$ & $\begin{array}{c}\text { Medicare } \\
\text { Beneficiaries } \\
\text { (Millions) }\end{array}$ \\
\hline 0 & 0 & 436 & 0 & - & 2,313 & 11.9 \\
\hline 1 & .91 & 459 & 6.5 & 59.6 & 341 & 4.1 \\
\hline 2 & 3.14 & 485 & 12.9 & 64.8 & 198 & 3.3 \\
\hline 3 & 5.10 & 501 & 17.9 & 64.5 & 111 & 3.8 \\
\hline 4 & 11.87 & 545 & 24.0 & 82.0 & 87 & 5.2 \\
\hline 5 & 9.34 & 567 & 19.8 & 72.5 & 39 & 2.8 \\
\hline 6 & 22.38 & 579 & 29.5 & 87.7 & 28 & 1.6 \\
\hline 7 & 30.78 & 557 & 34.6 & 83.3 & 22 & 2.8 \\
\hline 8 & 11.36 & 602 & 25.2 & 97.2 & 9 & 1.3 \\
\hline 9 & 10.46 & 691 & 24.7 & 100 & 3 & .6 \\
\hline 10 & 43.51 & 678 & 31.6 & 100 & 3 & .6 \\
\hline
\end{tabular}

Note: Figures in 2000 dollars. Means weighted by number of Medicare eligibles in a county.

histogram of average monthly, county-level consumer surplus for 2000 conditional on the county having at least one $\mathrm{M}+\mathrm{C}$ plan. The distribution is highly skewed, with most counties having very little consumer surplus and the eligibles of a few counties receiving large amounts of welfare.

The sources of consumer surplus. We use our estimates of the indirect utility function parameters to decompose the consumer surplus into the benefits from prescription drug coverage, the nonprescription drug components of plan quality, and the role of competition in determining consumer surplus. The recent political debate over whether (and how) to add prescription drug coverage to the Medicare program makes this analysis germane. Our estimates of the role played by drug benefits in consumer surplus can help inform policy makers as to the value to enrollees of adding those benefits to the Medicare program. More specifically, our estimates provide an estimate impact to Medicare beneficiaries of adding prescription drug benefits through private insurers, as President George W. Bush has recently proposed.

The value of prescription drug benefits. To examine the impact of prescription drug benefits on consumer surplus, we perform the following simple experiment. For 2000, we turn the drug

\section{FIGURE 2}

HISTOGRAM OF WEIGHTED MONTHLY CONSUMER SURPLUS FOR 2000 BY COUNTY CONDITIONAL ON CONSUMER SURPLUS BEING GREATER THAN ZERO

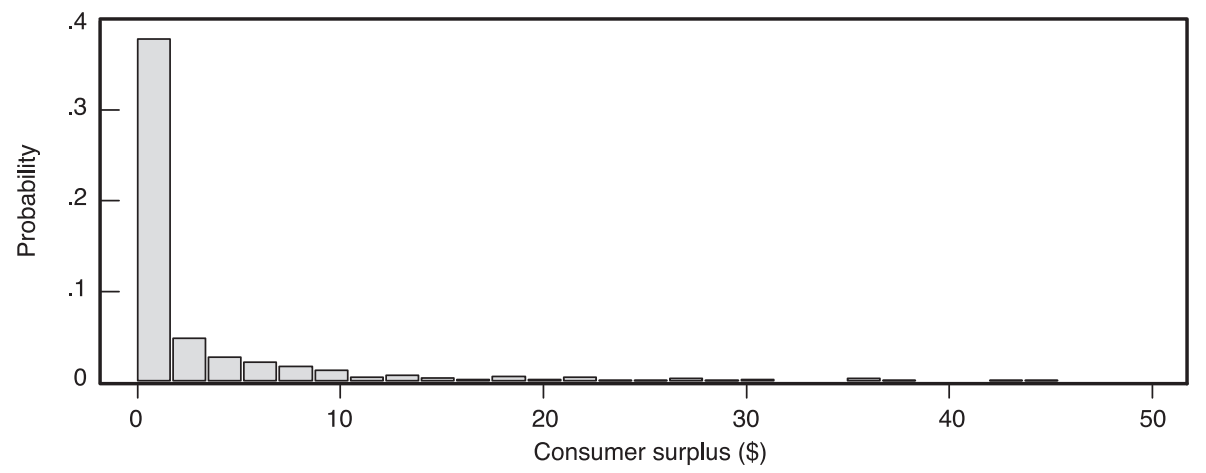


indicators, $d_{j m t}$ and $d_{j m t}^{97}$, off and then recalculate aggregate consumer surplus. Without the drug benefits, aggregate estimated consumer surplus is $\$ 2.29$ billion $-45 \%$ less than when drug benefits are allowed. The implication of these estimates is straightforward-a significant component of consumer benefit from the $\mathrm{M}+\mathrm{C}$ program is tied to the prescription drug benefit. The implied welfare gain from prescription drug coverage translates into an average annual benefit of $\$ 443$ for enrollees in an $\mathrm{M}+\mathrm{C}$ plan with drug benefits. This figure is reasonably close to other estimates of the value of prescription drug benefits. The average total drug expenditure less out-of-pocket expenses for Medicare enrollees with prescription drug coverage is $\$ 516$ (Poisal and Chulis, 2000). Thorpe and Atherly (2002) estimate the actuarial value of $M+C$ plan benefit structures, finding that the weighted average annual value of benefits is $\$ 471$. Our estimates also imply a significant growth in the value of prescription drug benefits. In 1993, the per-capita estimated annual value of drug benefits is approximately $\$ 65$.

Decomposing the relationship between consumer surplus and the number of plans. To examine the role of drug benefits, competition, and the unobserved plan quality on consumer surplus, we perform three experiments with our data for 2000. The object of these experiments is to better understand the reasons why counties with four plans generate approximately twelve times the consumer surplus as do monopoly counties. Comparing the change in consumer surplus within and across the experiments should highlight the source of the differences in consumer surplus between monopoly and quadropoly markets. Below we list the three experiments.

Experiment 1. We introduce three additional plans, identical in drug benefits and unobserved quality, to monopoly counties. In this experiment we assume all the plans are jointly owned and calculate the new equilibrium premiums. The CMS payment rate is assumed to be unchanged.

Experiment 2. The second experiment is identical to the first except that we increase the number of plans offering drug benefits so that the average plan has the same likelihood of offering drug benefits as a plan in a county with four plans (60\% versus $82 \%)$. We calculate consumer surplus with one and four plans. We run this experiment 50 times, since there is a random component to it, and report the mean results. The CMS payment rate is assumed to be unchanged.

Experiment 3. We focus on counties with four plans. In these counties we recalculate the equilibrium premiums while assuming the plans are jointly owned. All of the other characteristics of the plans and CMS payment rate are unchanged.

Table 5 reports the results of the experiments. They indicate that most of the difference in consumer surplus between monopoly markets and markets with four plans is due to premium competition. In the first row of Table 5 we report the results of the first experiment. Adding three plans increases consumer surplus from $\$ .91$ to $\$ 1.27$. That is, the difference in product variety between one-plan and four-plan counties accounts for $\$ .36$ of the $\$ 10.96$ difference. As mentioned above, plans in quadropoly markets are more likely to offer drug benefits. In the second experiment (second row of Table 5), we equate this probability (we do not adjust marginal cost in this experiment, so it is an upper-bound estimate of consumer surplus) and recalculate the monopoly premium. Monopoly plans with $82 \%$ of them now offering prescription drugs generate consumer surplus of $\$ 1.34$, a $\$ .43$ increase. When we add three identical plans to the monopoly counties in this experiment, consumer surplus increases to $\$ 2.13$.

The third row of Table 5 presents the results of the third experiment. Allowing joint ownership of the plans decreases consumer surplus from $\$ 11.87$ to $\$ 2.96$. That is, $\$ 8.91$ of the difference between consumer surplus in monopoly markets and quadropoly markets is due to increased premium competition. In this experiment, premiums increased from a mean of $\$ 18.27$ to $\$ 34.19$ with the increase in market power.

The difference between consumer surplus in these two classes of counties roughly breaks down as follows: $81 \%$ is from premium competition, $3 \%$ is from increased product variety, and $8 \%$ is due to a higher average prescription drug coverage (60\% versus $82 \%)$. On average, plans in quadropoly counties have better nonprescription drug quality (mean of -2.22 versus -2.56 ). The results of these experiments suggest that the difference in nonprescription drug quality accounts 
TABLE 5 Sources of Consumer Surplus Experiments

\begin{tabular}{|c|c|c|c|c|c|}
\hline $\begin{array}{l}\text { Initial } \\
\text { Number } \\
\text { of Plans }\end{array}$ & Experiment & $\begin{array}{c}\text { Mean } \\
\text { Implied } \\
\text { Non-Drug } \\
\text { Plan } \\
\text { Quality }\end{array}$ & $\begin{array}{c}\text { Initial } \\
\text { Percentage } \\
\text { of Plans } \\
\text { Offering } \\
\text { Drug } \\
\text { Coverage }\end{array}$ & $\begin{array}{c}\text { Initial } \\
\text { Equilibrium } \\
\text { Monthly } \\
\text { Per-Capita } \\
\text { Consumer } \\
\text { Surplus }\end{array}$ & $\begin{array}{c}\text { New } \\
\text { Equilibrium } \\
\text { Monthly } \\
\text { Per-Capita } \\
\text { Consumer } \\
\text { Surplus }\end{array}$ \\
\hline 1 & $\begin{array}{l}\text { Add } 3 \text { new plans, identical to the } \\
\text { monopolist, to the county owned by } \\
\text { the monopolist }\end{array}$ & -2.56 & 65.5 & $\$ 0.91$ & $\$ 1.27$ \\
\hline 1 & $\begin{array}{l}\text { Add } 3 \text { new plans, with } 85 \% \text { of the } \\
\text { plans having drug benefits, to the } \\
\text { county owned by the monopolist }\end{array}$ & -2.56 & 85.8 & $\$ 1.34$ & $\$ 2.13$ \\
\hline 4 & $\begin{array}{l}\text { Single ownership of all plans in the } \\
\text { county }\end{array}$ & -2.22 & 85.8 & $\$ 11.87$ & $\$ 2.96$ \\
\hline
\end{tabular}

for $8 \%$ of the remaining difference in consumer surplus between the two types of counties. Differences in the likelihood of offering drug benefits and unobserved plan quality are both probably a function of increased competition and more generous payment rates in four-plan counties (and perhaps interactions between the two). Decomposing the payment effects from the competition effects on plan characteristics is beyond the scope of this article.

In sum, prescription drug coverage appears to be the linchpin for the $\mathrm{M}+\mathrm{C}$ program to generate significant benefits for Medicare enrollees. The experiments suggest that there is significant welfare left on the table, since most counties have few, if any, plans. Counties with several plans generate significantly more consumer surplus, and increased premium competition in multiplan counties appears to be the primary reason for the dramatic increase in consumer surplus there.

\section{Conclusions}

In this article we estimate the welfare associated with the Medicare HMO program, now known as Medicare+Choice. We find that the creation of the $\mathrm{M}+\mathrm{C}$ program resulted in approximately $\$ 15.6$ billion in consumer surplus and $\$ 52$ billion in producer surplus from 1993 to 2000 (in 2000 dollars). The indirect utility parameter estimates imply that the majority of the consumer surplus generated in the program is directly attributable to the availability of prescription drug benefits. Competition also plays an important role in determining consumer surplus.

The appropriate role of private insurers in the Medicare market has been debated for over a decade. Congressional enthusiasm for the promotion of private insurance solutions to the "Medicare expenditure problem" seems to be waning. However, the results presented here suggest that the $\mathrm{M}+\mathrm{C}$ program generates substantial welfare for Medicare enrollees, and, from a policy perspective, competition in Medicare works for consumers. ${ }^{22}$ The findings presented here can also be interpreted as evidence that, through a reworking of the CMS payment structure, broad prescription drug coverage for Medicare enrollees can be achieved through the $\mathrm{M}+\mathrm{C}$ program.

${ }^{22}$ Dowd and Feldman (2002) articulate the case for Medicare to place more emphasis on the M+C program by reducing the federal government's underwriting of FFS costs. 


\section{Appendix}

- The appendix presents the results from the "first-stage" regression of the estimates of the utility parameters.

TABLE A1 First-Difference Estimates of the First-Stage Regressions

\begin{tabular}{|c|c|c|}
\hline \multirow[b]{2}{*}{ Parameter } & \multicolumn{2}{|c|}{ Dependent Variable } \\
\hline & $p_{j t}+p_{0 t}$ & $\ln \left(s_{j \mid D}\right)$ \\
\hline Mean Premium & $\begin{array}{c}0.26 \\
(0.024)\end{array}$ & $\begin{array}{r}-0.0023 \\
(0.0022)\end{array}$ \\
\hline Minimum Premium & $\begin{array}{c}0.47 \\
(0.019)\end{array}$ & $\begin{array}{r}0.0042 \\
(0.0015)\end{array}$ \\
\hline Maximum Premium & $\begin{array}{c}0.24 \\
(0.015)\end{array}$ & $\begin{array}{r}-0.00067 \\
(0.0015)\end{array}$ \\
\hline Mean Payment & $\begin{array}{r}-0.0072 \\
(0.0064)\end{array}$ & $\begin{array}{l}-0.0011 \\
(0.00060)\end{array}$ \\
\hline Minimum Payment & $\begin{array}{c}0.0034 \\
(0.0056)\end{array}$ & $\begin{array}{c}0.00044 \\
(0.00053)\end{array}$ \\
\hline Maximum Payment & $\begin{array}{c}0.020 \\
(0.0028)\end{array}$ & $\begin{array}{r}0.000017 \\
(0.00027)\end{array}$ \\
\hline Mean Number of Plans with Drugs & $\begin{array}{c}4.18 \\
(1.14)\end{array}$ & $\begin{array}{r}0.12 \\
(0.11)\end{array}$ \\
\hline Mean Number of Plans & $\begin{array}{c}0.18 \\
(0.067)\end{array}$ & $\begin{array}{c}-0.081 \\
(0.0063)\end{array}$ \\
\hline Lagged Number of Hospital Beds & $\begin{array}{r}-0.00022 \\
(0.00043)\end{array}$ & $\begin{array}{r}-0.000033 \\
(0.000041)\end{array}$ \\
\hline Lagged Number of Hospitals & $\begin{array}{c}1.36 \\
(0.11)\end{array}$ & $\begin{array}{r}0.0036 \\
(0.011)\end{array}$ \\
\hline Within $R^{2}$ & 0.84 & 0.080 \\
\hline$F$-test ( $p$-value) & $\begin{array}{r}2,738 \\
(0.0)\end{array}$ & $\begin{array}{r}40.4 \\
(0.0)\end{array}$ \\
\hline$N$ & 8,849 & 8,849 \\
\hline
\end{tabular}

Note: Other dependent variables include all of the dependent variables listed in Table 2 . The $F$-test is distributed $F(10 ; 8,878)$.

\section{References}

Atherly, A., Dowd, B., And Feldman, R. “The Effect of Benefits, Premiums, and Health Risk on Health Plan Choice in the Medicare Program." Mimeo, Division of Health Services Research and Policy, University of Minnesota, 2003.

Bell, A. “Medigap Sales Remain Stable.” National Underwriter, Vol. 103 (1999), p. 31.

Berry, S.T. "Estimating Discrete-Choice Models of Product Differentiation." RAND Journal of Economics, Vol. 25 (1994), pp. 242-262.

AND WALDFOGEL, J. "Free Entry and Social Inefficiency in Radio Broadcasting." RAND Journal of Economics, Vol. 30 (1999), pp. 397-420.

, Levinsohn, J., And Pakes, A. “Automobile Prices in Market Equilibrium.” Econometrica, Vol. 63 (1995), pp. 841-990.

—, AND — . "Voluntary Export Restraints on Automobiles: Evaluating a Trade Policy." American Economic Review, Vol. 89 (1999), pp. 400-430.

Bresnahan, T.F. And Reiss, P.C. "Entry in Monopoly Markets.” Review of Economics Studies, Vol. 57 (1990), pp. 531-544.

Brown, R.S., Clement, D.G., Hill, J.W., Retchin, S.M., et AL. "Do Health Maintenance Organizations Work for Medicare?" Health Care Financing Review, Vol. 15 (1993), pp. 7-23.

Buchmueller, T.C. "The Health Plan Choices of Retirees Under Managed Competition." Health Services Research, Vol. 35 (2000), pp. 949-976.

CARdell, N.S. "Variance Components Structures for the Extreme-Value and Logistic Distributions with Applications to Models of Heterogeneity." Econometric Theory, Vol. 13 (1997), pp. 185-213.

(c) RAND 2003. 
Cawley, J., Chernew, M., and McLaughlin, C. “HMO Participation in Medicare Managed Care.” Mimeo, Department of Health Management and Policy, University of Michigan, 2001.

Chernew, M., Gowrisankaran, G., And Scanlon, D. "Learning and the Value of Information: The Case of Health Plan Report Cards.” NBER Working Paper no. 8589, 2002.

Cutler, D.M. and Reber, S.J. "Paying for Health Insurance: The Trade-Off between Competition and Adverse Selection.” Quarterly Journal of Economics, Vol. 113 (1998), pp. 433-466.

Dowd, B. And Feldman, R. "Having It All: National Benefit Equity and Local Payment Parity in Medicare." Health Affairs, Vol. 21 (2002), pp. 208-214.

$-\frac{-}{-}$, And Christianson, J. Competitive Pricing for Medicare. Washington, D.C.: AEI Press, 1996. Care Financing Review, Vol. 17 (1996), pp. 35-57.

Goolsbee, A. And Petrin, A. "The Consumer Gains from Direct Broadcast Satellites and the Competition with Cable TV.” Mimeo, Graduate School of Business, University of Chicago, 2001.

Hausman, J.A. "Valuation of New Goods under Perfect and Imperfect Competition.” In T.F. Breshnahan and R.J. Gordon, eds., The Economics of New Goods, NBER Studies in Income and Wealth, Vol. 58. Chicago: University of Chicago Press, 1997.

Hellinger F.J. and Wong, H.S. "Selection Bias in HMOs: A Review of the Evidence." Medical Care Research \& Review, Vol. 57 (2000), pp. 405-439.

McFAdDEn, D. "Econometric Models of Probabilistic Choice.” In C.F. Manski and D. McFadden, eds., Structural Analysis of Discrete Data with Econometric Applications. Cambridge, Mass.: MIT Press, 1983.

Morgan, R.O., Virnig, B.A., DeVito, C.A., And Persily, N.A. "The Medicare-HMO Revolving Door (The Healthy Go In and the Sick Go Out).” New England Journal of Medicine, Vol. 337 (1997), pp. 169-175.

Nevo, A. "Measuring Market-Power in the Ready-to-Eat Cereal Industry.” Econometrica, Vol. 69 (2001), pp. $307-342$.

Petrin, A. "Quantifying the Benefits of New Products: The Case of the Minivan." Journal of Political Economy, Vol. 110 (2002), pp. 705-729.

Poisal, J.A. And Chulis, G.S. “Medicare Beneficiaries and Drug Coverage.” Health Affairs, Vol. 19 (2000), pp. $248-256$.

Riley, G., Tudor, C., Chiang, Y.P., Ingber, P., ET AL. "Health Status of Medicare Enrollees in HMOs and Fee-ForService in 1994." Health Care Financing Review, Vol. 17 (1996), pp. 65-76.

Rogers, J. AND Smith, K.E. Do Medicare HMOs Reduce Fee-for-Service Costs? Washington, D.C.: Price Waterhouse, 1995.

Royalty, A.B. And Solomon, N. "Health Plan Choice: Price Elasticities in a Managed Competition Setting." Journal of Human Resources, Vol. 34 (1999), pp. 1-41.

Rysman, M. "Competition Between Networks: A Study of the Market for Yellow Pages." Review of Economic Studies, forthcoming.

Strombom, B.A., Buchmueller, T.C., and Feldstein, P.J. "Switching Costs, Price Sensitivity and Health Plan Choice." Journal of Health Economics, Vol. 21 (2002), pp. 89-116

Thorpe, K.E. And Atherly, A. "Medicare+Choice: Current Role and Near-Term Prospects." Health Affairs-Web Exclusives, 2002, pp. W242-W252.

Town, R.J. "County-Level Evidence on Differential Selection Into M+C Plans.” Mimeo, Division of Health Services Research and Policy, University of Minnesota, 2003.

TrajtenberG, M. "The Welfare Analysis of Product Innovations, with an Application to Computed Tomography Scanners." Journal of Political Economy, Vol. 97 (1989), pp. 444-479.

U.S. Congressional Budget Office. "Testimony of Steven M. Lieberman on Medicare+Choice Before the Committee on Finance, United States Senate.” June 9, 1999.

Wholey, D. AND Burns, R. "Understanding Health Care Markets: Actors, Products, and Relations.” In S.S. Mick and M.E. Wyttenback, eds., Advances in Health Care Organization Theory. San Francisco: Jossey-Bass, 2003. 